\title{
Desafios da inclusão: a invisibilidade das pessoas com Transtorno do Espectro Autista no ensino superior
}

\author{
Inclusion challenges: the invisibility of people with Autism Spectrum Disorder \\ in higher education
}

Desafíos de la inclusión: la invisibilidad de personas con Trastorno del Espectro Autista en la educación superior

\section{Claudia Paola Carrasco Aguilar}

Professora mestre na Faculdade Pequeno Príncipe, Curitiba, Paraná, Brasil. claudia.aguilar@fpp.edu.br

ORCID - https://orcid.org/0000-0001-6334-7309

\section{Patricia Forte Rauli}

Professora doutora na Faculdade Pequeno Príncipe, Curitiba, Paraná, Brasil.

patricia.rauli@fpp.edu.br

ORCID - https://orcid.org/0000-0001-9415-9546

Recebido em 4 de maio 2020

Aprovado em 11 de agosto de 2020

Publicado em 30 de setembro de 2020

\section{RESUMO}

Autistas tem chegado ao ensino superior e se deparado com desafios. O objetivo desta pesquisa foi identificar, do ponto de vista do estudante com Transtorno do Espectro Autista (TEA) o processo de adaptação à universidade, as dificuldades enfrentadas, as estratégias utilizadas e os recursos oferecidos pelas universidades. A pesquisa, qualitativa exploratório descritiva, foi aprovada pelo Comitê de Ética em Pesquisa em Seres Humanos e realizada através de três Grupos Focais com autistas que frequentaram o ensino superior. Os resultados apontaram que, na adaptação à universidade, enfrentaram dificuldades relacionadas ao estigma, ao desconhecimento do TEA por parte da comunidade acadêmica, além de dificuldades causadas pelas características próprias do TEA, como a sobrecarga sensorial e emocional. Como estratégia de adaptação três participantes optaram por comunicar o diagnóstico à instituição de ensino superior, quatro relataram preferir que o diagnóstico não fosse revelado. Os participantes relataram dificuldades para obter adaptações didático-pedagógicas, apesar da existência de núcleos com essa finalidade. Apesar de cada autista demandar intervenções específicas, a IES necessita construir mecanismos que o acolham e favoreçam o processo de inclusão. Medidas universais, disponíveis a todo o corpo acadêmico, com foco em promover a equidade, defender e valorizar a diversidade e educar a comunidade do campus fornecendo informações sobre o TEA são necessárias não apenas para a inclusão do autista, mas para a construção de uma sociedade mais justa para todos.

Palavras-chave: Inclusão; autismo; Ensino Superior. 
http://dx.doi.org/10.5902/1984686X44082

\section{ABSTRACT}

Autists have come to higher education and are facing challenges. The aim of this research was to identify, from the point of view of the student with Autistic Spectrum Disorder (ASD) the process of adaptation to the university, the difficulties faced the strategies used and the resources offered by the universities. The qualitative descriptive exploratory research was approved by the Human Research Ethics Committee and conducted through three Focus Groups with autists who attended higher education. The results showed that, in adapting to the university, they faced difficulties related to stigma, lack of knowledge of ASD by the academic community, and difficulties caused by the characteristics of ASD, such as sensory and emotional overload. As an adaptation strategy, three participants chose to communicate the diagnosis to the higher education institution, four reported preferring not to reveal the diagnosis. Participants reported difficulties in obtaining didactic-pedagogical adaptations, despite the existence of nuclei for this purpose. Although each autistic person demands specific interventions, the HEI needs to build mechanisms that welcome it and favor the inclusion process. Universal measures, available to the entire academic body, focused on promoting equity, upholding and valuing diversity, and educating the campus community by providing information about ASD are necessary not only for the inclusion of the autistic, but for building a society fairer to everyone. Keywords: Inclusion; autism; college.

\section{RESUMEN}

Los autistas han llegado a la educación superior y se enfrentan a desafíos. El objetivo de esta investigación fue identificar, desde el punto de vista del estudiante con Trastorno del Espectro Autista (TEA), el proceso de adaptación a la universidad, las dificultades que enfrentaron, las estrategias utilizadas y los recursos ofrecidos por las universidades. Esta investigación exploratoria descriptiva cualitativa fue aprobada por el Comité de Ética de Investigación Humana y realizada a través de tres Grupos Focales con autistas que asistieron a la educación superior. Los resultados mostraron que, al adaptarse a la universidad, enfrentaron dificultades relacionadas con el estigma, la falta de conocimiento de los TEA por parte de la comunidad académica y las dificultades causadas por las características de los TEA, como la sobrecarga sensorial y emocional. Como estrategia de adaptación, tres participantes optaron por comunicar el diagnóstico a la institución de educación superior, cuatro informaron que preferían no revelar el diagnóstico. Los participantes informaron dificultades para obtener adaptaciones didáctico-pedagógicas, a pesar de la existencia de núcleos para este propósito. Aunque cada persona autista exige intervenciones específicas, la IES necesita construir mecanismos que la acojan y favorezcan el proceso de inclusión. Medidas universales, disponibles para todo el cuerpo académico, enfocadas en promover la equidad, defender y valorar la diversidad y educar a la comunidad del campus al proporcionar información sobre los TEA, son necesarias no apenas para la inclusión del autismo, sino también para construir una sociedad más justa para todos.

Palabras clave: Inclusión; autismo; Educación Superior. 
http://dx.doi.org/10.5902/1984686X44082

\section{Introdução}

Alguns autistas são invisíveis para seus colegas e professores: apesar das limitações impostas pelo transtorno, suas necessidades educacionais especiais (NEE) passam despercebidas durante sua vida acadêmica. Outros, alvo de bullying, desejam a invisibilidade.

Embora a legislação brasileira tenha avançado no processo de inclusão, há uma importante defasagem entre as políticas e concepções teóricas e a prática efetivamente estabelecida nos ambientes universitários. Não obstante, estudos internacionais recentes apontam para a efetividade das práticas inclusivas no ensino superior (GELBAR; SMITH; REICHOW, 2014; ANDERSON; STEPHENSON; CARTER, 2017; SHMULSKY; GOBBO, 2013).

O aumento da prevalência do Transtorno do Espectro Autista (TEA) associado às intervenções precoces que melhoram o prognóstico e às políticas inclusivas na educação de pessoas com deficiência culminou na ampliação do acesso dos autistas ao ensino superior. Porém, quando comparado a outras deficiências, o TEA apresenta maiores índices de abandono acadêmico, menor empregabilidade $\mathrm{e}$ mais comorbidades psiquiátricas (VAN HEES; MOYSON; ROEYERS, 2014; GELBAR; SMITH; REICHOW, 2014)

A participação de autistas no ensino superior vem aumentando em todo o mundo (GILLESPIE-LYNCH et al., 2015), enquanto as medidas necessárias para garantir sua permanência com equidade estavam, e ainda estão sendo construídas e implementadas.

Ainda que avanços possam ser observados, esta população tem sido, por muito tempo, pouco estudada e subestimada (ROBERTS; BIRMINGHAM, 2017). Além disso, os estudos relacionados raramente apresentam a perspectiva do estudante autista, focando na maioria das vezes, na perspectiva do outro- pesquisador, professor, profissional de saúde_- a respeito do mesmo.

Partindo destas considerações, o objetivo da presente pesquisa foi dar visibilidade e voz a autistas que frequentaram o ensino superior, com o intuito de identificar como se dá, do ponto de vista de estudantes com TEA, a adaptação à universidade, bem como contribuir para um processo de ensino-aprendizagem que seja inclusivo, em todas as suas dimensões. 


\section{Inclusão de Pessoas com Transtorno do Espectro Autista no Ensino Superior}

Segundo a Política Nacional de Educação Especial na Perspectiva da Educação Inclusiva, a educação inclusiva é fundamentada na concepção de direitos humanos, que conjuga igualdade e diferença como valores indissociáveis (BRASIL, 2008).

A Convenção sobre os Direitos da Pessoa com Deficiência, Decreto no 6.949/2009 (BRASIL, 2009), muda os paradigmas em relação às pessoas com deficiência, ao deixar de vê-las como alvos de caridade, de assistência médica e de proteção social e passar a considerá-las como sujeitos de direito, capaz de tomar decisões para sua vida com base em seu consentimento livre e esclarecido, como membros ativo da sociedade.

A Política Nacional de Proteção dos Direitos da Pessoa com Transtornos do Espectro Autista, regulamentada pelo Decreto no 8.368 (BRASIL, 2014), assegura o direito à educação em todos os níveis. Em 2015 foi aprovada a Lei no 13.146, que institui o direito de acesso ao sistema educacional inclusivo da pessoa com deficiência desde a educação infantil até a educação superior (BRASIL, 2015).

Os indicadores relativos ao número de matrículas acompanham o avanço dos marcos regulatórios no âmbito da inclusão. No ano de 2017 foram realizadas no Brasil 38.272 matrículas em cursos de graduação de estudantes com NEE. Este número vem crescendo nos últimos anos (INSTITUTO NACIONAL DE ESTUDOS E PESQUISAS EDUCACIONAIS ANÍSIO TEIXEIRA, 2018).

Em tal contexto, as Instituições de Ensino Superior (IES) são desafiadas a assumir a acolhida destes estudantes, numa realidade educacional mais complexa e exigente que a educação básica (CULLEN, 2015) e, ainda, são provocadas no sentido de assegurar condições adequadas para que possam realizar com qualidade seus estudos e concluir sua formação (DIAS SOBRINHO, 2010).

Conforme apontam Shmulsky e Gobbo (2013), adultos autistas cognitivamente capazes podem se beneficiar do ensino superior para se integrar com mais eficiência à comunidade, além de desenvolver habilidades para uma vida mais produtiva e independente, porém necessitam preparação e apoio adequados para maximizar a probabilidade de sucesso no ensino superior (ANDERSON; BUTT, 2017).

A educação superior é fator importante para melhorar a empregabilidade e para a independência financeira, além de contribuir para a participação das pessoas com TEA na 
comunidade (VANBERGEIJK; KLIN; VOLKMAR, 2008; VOLKMAR; WOLF, 2013). Sem apoio esses indivíduos são mais propensos a enfrentar o aumento da pobreza, taxas de desemprego mais altas, oportunidades precárias de progresso no emprego e discriminação. Há uma clara necessidade de encontrar intervenções eficazes para que os autistas possam levar vidas plenas e produtivas (VOLKMAR; WOLF, 2013).

A transição para o ensino superior é estressante para qualquer estudante (MORETT; HÜBNER, 2017), porém, para as pessoas com TEA, as deficiências nas habilidades de comunicação social amplificam este estresse (SHMULSKY; GOBBO, 2013). Os programas de apoio a estudantes com TEA no ensino superior encontrados na literatura variaram de mentores e grupos de apoio social a locais diferenciados para realizar avaliações acadêmicas, além de iniciativas para divulgar o TEA direcionadas a toda a comunidade acadêmica (ANDERSON; STEPHENSON; CARTER, 2017; AMES et al., 2016).

Em face da ampla diversidade da apresentação, a assistência deve ser individualizada. A trajetória de desenvolvimento de cada autista é única e a gravidade dos sintomas pode variar em relação ao tempo, o que torna mais difícil estabelecer um programa que sirva para todos (GELBAR; SMITH; REICHOW, 2014).

Não obstante a complexidade da temática, as condições oferecidas pelas instituições de Ensino Superior para atender às necessidades destes estudantes são, ainda, bastante precárias. A lacuna na formação de professores é apontada como uma das principais dificuldades no processo de inclusão (GATTI, 2010; MIRANDA; GALVÃO FILHO, 2012; GLAT; FERNANDES, 2005; RUARO; BEHRENS, 2014).

Professores universitários necessitam de preparo que vai além do conhecimento científico (TAVARES; SANTOS; FREITAS, 2016), a inclusão pressupõe mudanças que dependem da formação e atuação do professor e está amplamente associada às habilidades interpessoais do professor (ROSIN-PINOLA; DEL-PRETTE, 2014).

Neste sentido as IES precisam responsabilizar-se por incluir a temática em seus programas de formação docente bem como oferecer instâncias que possam apoiar discentes e docentes no processo de inclusão.

\section{O Transtorno do Espectro Autista: história, conceitos e características}

Apesar de diversos estudiosos terem reconhecido padrões atípicos de neurodesenvolvimento, o estabelecimento do TEA como diagnóstico isolado é 
http://dx.doi.org/10.5902/1984686X44082

relativamente recente: até 1980 o diagnóstico do TEA estava englobado na categoria diagnóstica da esquizofrenia infantil (SADOCK; SADOCK; RUIZ, 2017).

Eugene Bleuler, em 1911, foi o primeiro a utilizar o termo "autismo" para descrever a dificuldade de interação social e a tendência ao isolamento em pacientes com esquizofrenia (BLEULER, 1911). O autismo como diagnóstico isolado foi utilizado quase simultaneamente por Leo Kanner e por Hans Asperger para descrever quadros diferentes, porém com algumas características em comum, como isolamento extremo, obsessividade, estereotipias e ecolalia (ASSUMPÇÃO JÚNIOR; KUCZYNSKI, 2015).

Com a publicação do DSM-5, em 2013, foi instituído como diagnóstico único o TEA com diferentes níveis de gravidade, um transtorno do neurodesenvolvimento definido por comprometimento do relacionamento social, repertório repetitivo e estereotipado de comportamentos, dificuldades de linguagem e insistência em determinadas rotinas não funcionais (AMERICAN PSYCHIATRIC ASSOCIATION, 2013).

O Brasil adota a Classificação Estatística Internacional de Doenças e Problemas Relacionados à Saúde (CID), utilizada por todos os Estados Membros da Organização Mundial da Saúde (OMS). Atualmente está em vigor a CID-10, que no grupo dos Transtornos Globais do Desenvolvimento (F84) inclui o Autismo infantil, o Autismo atípico e a Síndrome de Asperger (ORGANIZACÃO MUNDIAL DA SAÚDE, 1993).

O TEA é um transtorno com apresentações diversificadas, caracterizado por dificuldades persistentes na comunicação e na interação social associadas a padrões restritos e repetitivos de comportamento, presentes desde a infância e com limitação e prejuízo no funcionamento diário (SADOCK; SADOCK; RUIZ, 2017).

Os sintomas devem estar presentes nas primeiras etapas do neurodesenvolvimento e podem não estar totalmente manifestos até que a demanda social exceda suas capacidades ou podem ficar mascarados por algumas estratégias de aprendizado ao longo da vida. Devem causar prejuízo clinicamente significativo nas áreas social, ocupacional ou outras áreas importantes de funcionamento atual do paciente, e não devem ser mais bem explicados por deficiência cognitiva ou atraso global do desenvolvimento (AMERICAN PSYCHIATRIC ASSOCIATION, 2013).

Os sintomas relacionados à interação social podem ser desde a limitação na reciprocidade social e emocional, limitação nos comportamentos de comunicação não verbal utilizados para interação social ou limitação em iniciar, manter e entender relacionamentos, a dificuldades com adaptação de comportamento para se ajustar as 
diversas situações sociais (LAI; LOMBARDO; BARON-COHEN, 2013). Da mesma maneira padrões restritos e repetitivos de comportamento, interesses ou atividades podem se apresentar como movimentos repetitivos e estereotipados no uso de objetos ou na fala, insistência nas mesmas coisas, aderência inflexível às rotinas ou padrões ritualísticos de comportamentos verbais e não verbais, interesses restritos que são anormais na intensidade e foco, e hiper ou hiporreatividade a estímulos sensoriais (AMERICAN PSYCHIATRIC ASSOCIATION, 2013)

$\mathrm{Na}$ figura 1, adaptada de imagem da artista plástica autista Rebecca Burgess (BURGUESS, 2018), podemos visualizar a variação das características do TEA.

Figura 1 - Espectro Multidimensional do Autismo

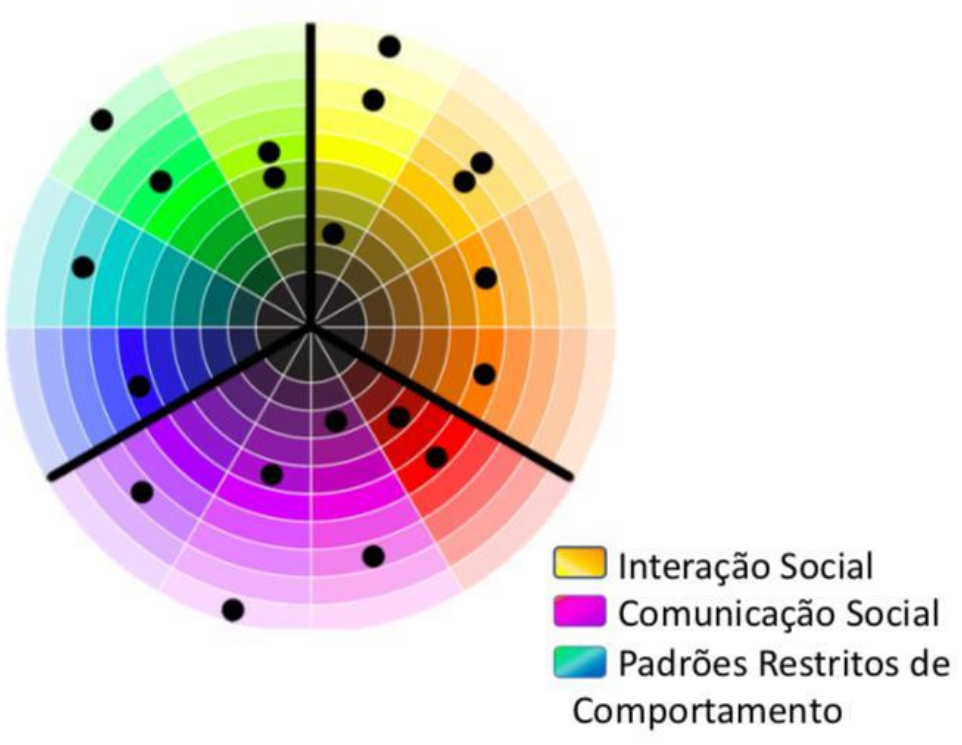

Fonte: Adaptado de Rebecca Burguess, (2017).

O nível de gravidade deve ser avaliado em relação à interação/comunicação social e em relação ao comportamento restrito. É importante destacar que em todos os níveis há necessidade de suporte, o que varia é a intensidade em que esse suporte é requerido (AMERICAN PSYCHIATRIC ASSOCIATION, 2013).

Estudos epidemiológicos do TEA ao longo do tempo se tornam difíceis ou talvez até impossíveis ao considerarmos a grande variação de seus critérios diagnósticos (RAPIN; TUCHMAN, 2011). Há duas décadas, estimava-se que o TEA afetava de 1 a 5 em cada 10.000 crianças (ASSUMPÇÃO JÚNIOR; PIMENTEL, 2000). Atualmente estima-se uma prevalência de 1:48 (BAIO et al., 2018). O aumento geral da prevalência de TEA é multifatorial e inclui a melhora no reconhecimento dos sintomas do TEA, o aumento do 
http://dx.doi.org/10.5902/1984686X44082

diagnóstico tardio e a capacidade de identificar crianças mais precocemente (ADREON; DUROCHER, 2007).

Com relação à genética e alterações estruturais, estudos de imagem têm demonstrado diversas alterações estruturais relacionadas ao autismo. Inúmeras anormalidades foram relatadas em quase todas as regiões do cérebro em indivíduos com TEA (WATERHOUSE, 2013). Alterações estruturais dos gânglios da base e do cerebelo também estão sendo relacionadas (FRYE, 2018). O autismo e o alto QI compartilham alterações estruturais como o aumento do volume do cérebro, crescimento cerebral acelerado, aumento das habilidades sensoriais e viso espaciais, além de funções sinápticas aumentadas (CRESPI, 2016).

O padrão de conectividade idiossincrático no cérebro de cada indivíduo com TEA propicia maneiras diversas de interagir com o meio e de interpretar a realidade (HAHAMY; BEHRMANN; MALACH, 2015). A conectividade cerebral atípica tem sido relacionada a fatores como a rigidez cognitiva e hiper-reatividade emocional (SWAIN et al., 2015), as alterações no processamento sensorial básico (CHANG et al., 2014) e no processamento emocional social (AMEIS; CATANI, 2015). A conectividade reduzida nas conexões do giro fusiforme com a amígdala e o hipocampo pode explicar a falta de reconhecimento de expressões emocionais (AMEIS; CATANI, 2015).

Estudos com famílias de autistas demonstraram que diversas características ou traços apresentam importante herdabilidade (CARAYOL et al., 2011). Pais de crianças com TEA podem apresentar um conjunto subclínico de traços conhecidos como "Fenótipo Ampliado do Autismo" (RUZICH et al., 2015). Fatores genéticos diversos, como mutações raras de grande efeito ou variantes comuns de pequeno efeito, exercem um papel fundamental na etiologia assim como fatores ambientais iniciais contribuem para o risco (LAI; LOMBARDO; BARON-COHEN, 2013). Estudos com gêmeos sugeriram que o autismo tem mais de $80 \%$ de herdabilidade, com importante associação de mecanismos epigenéticos e interação gene-ambiente específica cujo mecanismo ainda não está bem estabelecido (MAZEFSKY et al., 2008).

\section{Materiais e métodos}

A coleta de dados desta pesquisa de natureza qualitativa, do tipo exploratório descritiva, foi realizada através de três Grupos Focais. Como critério de inclusão foi considerado o diagnóstico de TEA, conforme critérios do DSM-5, ou Síndrome de Asperger, 
http://dx.doi.org/10.5902/1984686X44082

segundo os critérios da CID-10, e o fato dos participantes terem frequentado o ensino superior por pelo menos seis meses. Foram excluídos os participantes que não haviam sido diagnosticados por médicos e os que apresentavam outro tipo de deficiência além do TEA. A pesquisa contou com sete participantes, que receberam a denominação de P1 a P7, recrutados por carta-convite.

Tabela 1 - Perfil dos Participantes

\begin{tabular}{l|l|l|l|l|l} 
PARTICIPANTE & SEXO & IDADE & CURSO & SITUAÇÃO & DIAGNÓSTICO \\
\hline P1 & M & 18 & Psicologia & Cursando & $\begin{array}{l}\text { Síndrome de } \\
\text { Asperger }\end{array}$ \\
\hline P2 & F & 23 & Medicina & Cursando & TEA - Nível 1 \\
\hline P3 & M & 29 & $\begin{array}{l}\text { Direito } \\
\text { Filosofia }\end{array}$ & $\begin{array}{l}\text { Concluiu } \\
\text { Abandonou }\end{array}$ & $\begin{array}{l}\text { Síndrome de } \\
\text { Asperger }\end{array}$ \\
\hline P4 & F & 21 & Psicologia & Cursando & TEA - Nível 1 \\
\hline P5 & M & 38 & Direito & Concluiu & $\begin{array}{l}\text { Síndrome de } \\
\text { Asperger }\end{array}$ \\
\hline P6 & $\mathrm{M}$ & 23 & Psicologia & Cursando & TEA - Nível 2 \\
\hline P7 & $\mathrm{M}$ & 22 & Farmácia & Cursando & $\begin{array}{l}\text { Síndrome de } \\
\text { Asperger }\end{array}$
\end{tabular}

Fonte: Dados da pesquisa (2019).

A pesquisa seguiu os preceitos éticos da Resolução no 466 de 2012 do Conselho Nacional de Saúde. Os entrevistados foram informados sobre o caráter voluntário da participação na pesquisa, sobre o anonimato, sigilo das informações e da sua autonomia para desistir da pesquisa em qualquer momento que desejassem. Foi, ainda, assegurado que os dados seriam utilizados estritamente para os fins da pesquisa. Todos os entrevistados que aceitaram participar da pesquisa assinaram o Termo de Consentimento Livre e Esclarecido (TCLE) antes de iniciá-la. O projeto de pesquisa foi encaminhado ao Comitê de Ética em Pesquisa e apenas após a sua aprovação pelo parecer 2.331.010 é que se deu início à coleta dos dados.

Os dados coletados foram apreciados seguindo a metodologia de análise de conteúdo, um conjunto de técnicas de análise das comunicações que tem como objetivo extrair indicadores que permitam a inferência de conhecimentos relativos às condições de produção/recepção destas mensagens (BARDIN, 2011). De acordo com Silva e Fossá (2015), a análise de conteúdo procura conhecer aquilo que está por trás do significado das palavras. 
http://dx.doi.org/10.5902/1984686X44082

Os indicadores foram extraídos através de procedimentos sistemáticos e objetivos de descrição do conteúdo das mensagens e os dados foram trabalhados em três fases distintas: pré-análise, exploração do material e tratamento dos resultados.

$\mathrm{Na}$ fase de pré-análise foi realizada uma leitura flutuante dos documentos utilizados, seguida pela seleção de trechos de falas dos participantes. A segunda fase consistiu na exploração do material com a classificação e agregação das informações em categorias temáticas. O tratamento dos resultados, por inferência e interpretação das falas dos participantes com base na literatura utilizada como referencial teórico, consistiu na última fase da metodologia de análise do conteúdo.

\section{Análise de resultados e discussão}

Seguindo as etapas previstas na metodologia, os dados coletados foram organizados em três categorias de análise: a) Dificuldades Enfrentadas; b) Mecanismos de Adaptação; e, c) Recursos da IES.

$\mathrm{Na}$ categoria (a) Dificuldades Encontradas foram incluídas as falas relacionadas ao Estigma, ao Desconhecimento e às Características Próprias do TEA - como o Meltdown e Shutdown. Na categoria (b) Mecanismos de Adaptação foram colocados os discursos relacionados à Comunicação do Diagnóstico e sua interferência no percurso universitário, ao Relacionamento com Colegas e ao Relacionamento com os professores. Na categoria (c) Recursos da IES, foram analisadas as Adaptações didático-pedagógicas, os Núcleos de Apoio e o Conhecimento do Professor como recurso de adaptação.

Apresenta-se, a seguir, a análise das categorias realizada a partir do referencial teórico.

\section{Estigma}

O peso do diagnóstico e do estigma foi diversas vezes referido pelos participantes.

Eu já escutei de vários professores que eu não parecia ter autismo que eu devia ser reavaliado. (P1).

\footnotetext{
Eu tenho noção de que a aparência que eu passo é bem atípica do que as pessoas entendem que é o autista. As pessoas acham que o autista não fala, que o autista que não sai de casa, que autista não faz faculdade, que o autista não (...) e tem autistas que realmente não fazem todas essas coisas. Não estou dizendo que ele não existe, mas também não estou dizendo que eu não existo dentro disso entendeu? (P2).
} 
http://dx.doi.org/10.5902/1984686X44082

Conforme aponta Goffman (1998), como o estudante do ensino superior com TEA não se encaixa no estereótipo de autista, alguém sem capacidade intelectual para a educação superior, fica clara a tendência do grupo social de excluí-lo da categoria de "autista" e a incluí-lo em outra "menos desejável": a categoria de indivíduos simuladores ou com outros transtornos mentais.

Goffman (1988) refere, ainda, que o indivíduo estigmatizado se sente exposto, em exibição, conforme apontado pela fala de um dos participantes.

As pessoas olham como se eu fosse um bicho do zoológico. É difícil. (P2)

Por outro lado, ao explicitar o diagnóstico o autista se sente aliviado por não ter que se forçar a situações desconfortáveis:

Eu tenho experiência assim bem negativa de quando os professores ainda não sabiam né e a gente não falava, quer dizer, minha mãe não falava, que eu tinha autismo e outras coisas. Lembro de uma vez que a professora ficou assim, sabe me chamando a atenção para eu ficar olhando para ela e não conseguia porque o olhar era demais, era bem esmagador, e hoje assim a gente está cuidando para avisar em toda a instituição que eu estou entrando, assim, de ensino. (P6).

O estigma relacionado a outros indivíduos com NEE ou com outros transtornos mentais também ficou evidenciado no discurso dos participantes.

O medo que as pessoas têm de lidar com quem tem transtornos mentais e emocionais (...) que tem muito medo de ter esses diagnósticos e precisar de tratamento. Porque sabem que vão sofrer estigma, então elas não saem da condição de procurar ajuda porque elas já sabem que vão sofrer. (P2).

Para Goffmann (1988), o indivíduo estigmatizado se sente inseguro em relação à maneira como o identificarão e o receberão, por não saber o que os outros estão realmente pensando dele.

O aluno é visto como um problema e não como alguém que tem que ser tratado de uma maneira adequada, então isso não é só para os professores, essa discussão (sobre revelar ou não o diagnóstico). E aí, nessa discussão, as pessoas com quem eu trabalho não sabem desse diagnóstico e eu não vou falar porque eu sei que isso para eles é um problema. (P5).

Quando eu cheguei no outro lugar que eu comecei a trabalhar, antes desse que eu estou agora, o setor que eu estava que era o departamento jurídico. O pessoal lá meio que me tratava como um como um ret (...) (pausa) um retardado, um incapaz (...) me passavam as coisas mais fáceis é, é, se dirigiam a mim falando como se estivessem se dirigindo a uma criança de 4 anos, foi um pouco chato. (P3). 
http://dx.doi.org/10.5902/1984686X44082

$\mathrm{Na}$ literatura, um estudo recente encontrou correlação entre a revelação do diagnóstico de Síndrome de Asperger e a redução do estigma percebido em estudantes de nível superior (BROSNAN; MILLS, 2015). Ações dirigidas a toda a comunidade acadêmica, como rodas de conversa e serviços de apoio universais auxiliam na redução do estigma (MATTHEWS; LY; GOLDBERG, 2014; VAN HEES; MOYSON; ROEYERS, 2014; COX et al., 2017).

\section{Desconhecimento}

O desconhecimento do TEA por parte dos colegas e professores foi repetidamente mencionado pelos participantes.

Pensam que o autista é aquele alto, aquele grau mais elevado que a pessoa não sai de casa aí eu tenho que explicar para as pessoas. (P1).

A gente não liga que as pessoas não saibam sobre, juro, não tem problema elas não saberem. O problema é elas não se dignarem a aprender, isso dói, entendeu? Eu não ligo de ter que explicar 30 vezes desde que a pessoa que esteja me escutando queira realmente entender o que que está se passando dentro de mim e porque que eu tenho $\mathrm{X}$ ou $\mathrm{Y}$ comportamento. (P2).

O discurso dos participantes confirma a necessidade relatada na literatura a respeito da lacuna de conhecimentos relacionados às pessoas com deficiência no âmbito do ensino. Conforme destacam Azevedo et al (2019), as instituições de ensino devem viabilizar condições para atender pessoas com deficiência de forma inclusiva, oferecendo estruturas físicas e pedagógicas adequadas.

\section{Características Próprias do TEA}

A repercussão das características próprias do TEA no meio acadêmico aparece na fala dos participantes, conforme a seguir:

Ou então você vai lá na frente e começa a falar (pausa) e quando finalmente você consegue pegar a linha do raciocínio e começa a falar é difícil parar. Tipo a gente não tem essa noção de que esse momento, em que a gente tem ou parar de escrever, ou parar de dizer, ou parar de raciocinar sobre aquilo. (P2).

Eu sou o típico aluno que incomoda os colegas (...) Eu era aquela pessoa que ok o grupo está apresentando "eu tenho uma pergunta!!!", todo mundo quieto, "eu tenho uma pergunta!!! Eu quero falar, eu quero comentar", eu quero isso, eu quero aquilo, porque eu tenho conhecimento, eu sei, eu quero compartilhar porque eu acho isso legal, mas as outras pessoas não acham isso legal. (P4). 
http://dx.doi.org/10.5902/1984686X44082

Os participantes falam sobre disfunção executiva comum no TEA, corroborando o já descrito na literatura: autistas apresentam dificuldade para perceber que já discorreram 0 suficiente sobre um tópico específico e resistem às tentativas de mudar o tópico quando este faz parte de seus interesses restritos (ANDERSON; BUTT, 2017).

Eu sofri mais no ensino fundamental e no ensino médio que era mais difícil, no ensino superior não foi tanto. No ensino superior eu acabei caindo em uma turma na faculdade que era mais interessada. (P5).

Comportamentos inadequados elevam o estresse prejudicando o desempenho acadêmico, bem como podem ocasionar bullying, mas os interesses em comum com seus pares no ensino superior podem tornar mais simples a fluência de conversas para alguns autistas (GILLESPIE-LYNCH et al., 2017).

Características observadas nas falas dos participantes, como o vocabulário avançado, a fala formal ou afetada e com volume inadequado, são descritas na literatura (ADREON; DUROCHER, 2007). Também foi evidenciada nos grupos focais a dificuldade de envolverse em conversas recíprocas e em levar em conta as necessidades do ouvinte ao falar, conforme descrito por Anderson, Stephenson e Carter (2017).

\section{Ansiedade}

A ansiedade foi frequentemente relatada pelos participantes. Apesar de não fazer parte dos critérios diagnósticos do TEA, os Transtornos da Ansiedade apresentam alta taxa de comorbidade, principalmente nos autistas de alto funcionamento (SWAIN et al., 2015).

Apresentar trabalho é muito difícil para mim, eu tenho muito ataque de pânico e ansiedade mesmo tomando remédio não ajuda e os professores vem que estou tendo esse ataque e eles praticamente não fazem nada. Eles só falam assim: "você tem que relaxar", "É assim mesmo", "Como é que você vai apresentar um TCC"? (P1)

Eu fico muito hiperativo e começo a olhar para o chão me dá uma ansiedade uma dor aqui no peito sinto muita vontade de chorar. (P1).

Em relação ao Transtorno de Ansiedade Social (TAS), a comorbidade com TEA é de $17 \%$ em crianças e adolescentes e $22 \%$ em adultos, enquanto que na população adulta sem TEA a prevalência de TAS é estimada em 2.8\% (SWAIN et al, 2015). Kerns e cols. (2017) relatam sintomas de ansiedade específicos para o TEA que incluem hipersensibilidade, dificuldade para reconhecer as emoções, comportamentos repetitivos e inflexibilidade com as rotinas. 
http://dx.doi.org/10.5902/1984686X44082

\section{Alterações Sensoriais}

O cérebro humano é um processador sensorial cuja função principal é perceber, integrar, interpretar e depois facilitar a resposta coordenada apropriada às informações visuais, táteis, auditivas, olfativas e proprioceptivas presentes no mundo ao nosso redor (CHANG et al., 2014).

E aí quando eu vi eu não tinha mais condição de filtrar o ambiente, porque assim (...) para mim o ambiente é muita coisa. Entendeu? Tudo para nós é em primeiro plano. Enquanto eu estou aqui olhando para vocês e olhando para os meninos, eu estou escutando o barulho do ar. Entendeu? (P2).

Eu tenho a tendência, geralmente, a ficar (...) fora de sala de aula, até eu cansar, então às vezes eu fico na porta e aí perguntam: "Por que que você não ficou lá dentro?". Porque eu não gosto, está todo mundo conversando, tá uma barulheira, tá abafado, tá quente. (P4).

Me lembro de uma vez que a professora ficou assim, sabe, me chamando a atenção para eu ficar olhando para ela. Não conseguia porque o olhar era demais, era bem esmagador. (P6).

É melhor eu sentar na frente pela questão dos barulhos e não tem tanta gente na frente passando (...) isso me desconcentra. (P6).

Os achados da pesquisa confirmam Chang et al (2014) quando relatam que a incidência de disfunções sensoriais em autistas é alta. Para os autores, estímulos sensoriais toleráveis podem ser considerados estímulos aversivos para um autista, a ponto de gerar angústias e sofrimentos incapacitantes.

Um espaço físico com pouco estímulo sensorial, como uma sala com pouca iluminação, baixo ruído e ausência de odores onde os alunos podem ficar sozinhos por algum tempo, tem mostrado eficácia quando há sobrecarga sensorial. Este "local silencioso" também pode ser obtido com o uso de fones de ouvido para abafamento de ruídos (SARRETT, 2018).

\section{Meltdowns e Shutdowns}

A sobrecarga de informações sensoriais ou emocionais com uma consequente sobrecarga da capacidade de processar as informações recebidas pode levar a respostas caracterizadas pela perda temporária do controle emocional. Quando a pessoa está sendo incapaz de lidar com estes estímulos pode ocorrer um desligamento, o shutdown, ou um meltdown com descontrole emocional e comportamentos externalizantes autolesivos como bater a cabeça, se arranhar ou morder (HALIM; RICHDALE; ULJAREVIC, 2018). 
http://dx.doi.org/10.5902/1984686X44082

Uma participante descreve um episódio de meltdown, que ela chama de "crise autista".

E quando eu tenho crise fico bem mais estereotipada. Eu balanço porque é a forma de eu me acalmar eu já não olho no olho nas pessoas por muito tempo direto, assim, então aí eu não olho mesmo (...) quando entro em crise forte assim eu chego num ponto de despersonalização que eu não sei o que está acontecendo e eu só entro em movimento repetitivo. (P2).

No trecho a seguir a participante descreve um possível período de shutdown, com a impossibilidade de sair voluntariamente dessa condição.

Mas minhas crises, às vezes, eu não consigo sair de casa (...) porque eu não consigo sair da crise, entendeu? Eu não consigo levantar, abrir a porta e sair de carro. (P2).

Hatfield et al (2018) afirmam que mapear as especificidades sensoriais do autista, bem como os possíveis gatilhos para o meltdown ou shutdown, foram estratégias utilizadas com sucesso em programas de transição de adolescentes com TEA para o ensino superior.

\section{Comunicação do Diagnóstico}

Na categoria Comunicação do Diagnóstico estão agrupadas as falas referentes à revelação do diagnóstico autista no ambiente acadêmico, se os professores ou colegas sabem que o aluno tem diagnóstico de TEA e como essa informação foi recebida.

Dos sete participantes da pesquisa três comunicaram o diagnóstico à IES, dois obtiveram o diagnóstico durante o curso. Dois somente tiveram diagnóstico após terminarem a graduação. Três participantes referiram preferir ficar invisíveis e não comunicar o diagnóstico à IES.

Eu acho que muitas pessoas da sala não sabem que eu tenho esse diagnóstico. (P1).

Inclusive um professor falou assim para mim na hora em que eu peguei e falei (do diagnóstico). Ele falou: "olha eu acho que você deve ser reavaliada então vou falar para você um telefone". Começou me empurrar coisas tipo "esse não é o teu diagnóstico vamos rever" (pausa longa) (...) não é isso que eu quero, quero ser acolhida dentro diagnóstico que eu tenho seja ele qual for. (P2).

Não sei, na verdade é que a minha experiência com professores que sabem do diagnóstico não foi muito positiva, foram tipo: "Ok, vamos falar para a turma inteira e colaborem com o coleguinha". (P4).

O aluno é visto como um problema e não como alguém que tem que ser tratado de uma maneira adequada. (P5). 
http://dx.doi.org/10.5902/1984686X44082

A gente está cuidando para avisar. Em toda a instituição que eu estou entrando, assim, de ensino, como foi falado aqui quando eu entrei, eu tenho né a questão autista, mas eu percebo que alguns professores ficam não sabendo (P6).

Os dados encontrados assemelham-se a um estudo com a participação de autistas em que dois, dos nove alunos participantes, receberam diagnóstico formal de TEA depois de concluir faculdade. Muitos estudantes não conheciam seu diagnóstico, outros sabiam, mas optaram por não divulgar o diagnóstico. Alunos que o revelam muitas vezes só o fazem para um grupo restrito de pessoas e somente quando julgam necessário (COX et al., 2017)

$\mathrm{Na}$ literatura encontramos um estudo que correlaciona o conhecimento do diagnóstico de TEA à diminuição do estigma em relação aos comportamentos típicos, o que pode facilitar a procura pelos serviços de apoio (BROSNAN; MILLS, 2015).

\section{Relacionamento com colegas}

Participantes relataram dificuldades no relacionamento com colegas.

E a gente também é muito impulsivo, né? O professor, ele pergunta uma coisa, que eu acho muito fácil, para uma pessoa e eu acabo respondendo por ela (...) Aí minha colega: "cala a boca não foi para você". (P1).

Várias vezes isso aconteceu comigo também, muitas vezes de saber mais do que todo mundo, de falar. Demorei muito tempo para aprender que isso era socialmente aceito ou não muito bem aceito (...) as pessoas não gostavam. (P5).

diálogo a seguir demonstrou que a situação é comum aos participantes do grupo, ficando perceptível a falta de habilidades sociais e de comunicação.

É difícil para mim entrar em trabalhos em grupo porque muitos amigos meus não tem paciência tipo e eu domino o conteúdo certinho eu tento mas... (P1).

Saiu assim do nada (...) Aí chamam a gente de arrogante, de metido, de mimado. (P1).

As pessoas acham que eu estou sendo arrogante, mas eu sei aquilo, então se eu estou falando é porque (...). (P3).

Outras situações, como a exposição e o questionamento do diagnóstico também influenciaram no relacionamento com os colegas.

Havia pessoas dentro da minha sala comentando que na verdade eu usava meu transtorno como forma de os professores terem compaixão de mim, entendeu? E que ele não é real. É muito dolorido, é muito dolorido. Eu fiquei num estado assim (...) e me descompensa de tal forma que tira uma semana assim, até eu me reorganizar. (P3). 
http://dx.doi.org/10.5902/1984686X44082

A dificuldade de se integrar ao grupo foi, em diversas ocasiões, citada pelos participantes.

Para fazer trabalhos em grupo sempre acabo ficando por último. (P1).

Assim, eu não puxo papo, né? Geralmente eles que puxam, né? Mas eu posso conversar de boa (...) Ah, fora de sala de aula? Eu fico sozinho (...) Prefiro. (P6).

(...) normalmente eu planejo alguma coisa e o grupo não se integra a isso. (P7).

Apesar das dificuldades evidentes no relacionamento com os pares, os participantes não relataram nenhuma estratégia para interagir de maneira mais efetiva com os colegas. A literatura enfatiza que as dificuldades para a inclusão estão amplamente associadas a dificuldades interpessoais que constituem desafios tanto para as interações com o professor como para as interações com os demais colegas (MIRANDA; GALVÃO FILHO, 2012)

Neste contexto, White et al (2017) observam que obter apoio de um grupo social pode ajudar a prevenir o isolamento e o abandono do curso. Programas de treinamento de habilidades sociais e de comunicação têm se mostrado eficazes nas IES, inclusive em programas de transição direcionados a autistas no ensino médio, com a finalidade de instrumentalizar o estudante para os novos desafios que o ensino superior propõe (WEHMAN et al., 2014; SANTIAGO; SANTOS, 2015; GELBAR; SMITH; REICHOW, 2014; WONG et al., 2015).

\section{Relacionamento com os professores}

Neste grupo avaliou-se como os participantes percebem seu relacionamento com os professores.

\begin{abstract}
E as vezes é bem complicado de lidar com o professor nesse sentido. Até porque com a questão da autoridade, eu vejo muitos professores que se sentem ameaçados quando alguém sabe mais. Aí você vem explicar e questionar e o professor não está preparado para isso, porque o professor acha que ele é a instância máxima, que está certo e que não tem como argumentar com ele. "Você é aluno e eu sou professor". . . Vira uma questão mais vertical, e eu tenho muita dificuldade. (P4).
\end{abstract}

Se um professor, assim, é meio desorganizado, assim, se é um professor, assim, que é meio neurótico, ou não gosta muito, assim, de ser muito questionado, assim, que já teve problemas assim, aí fica difícil. Agora se for um professor prestativo, compreensivo assim, aí tudo bem. (P7). 
http://dx.doi.org/10.5902/1984686X44082

Aqui também se percebe a ausência de estratégias. Autistas podem se beneficiar com treinamento individual desde antes do início do primeiro semestre, para ajudá-los a se comunicar de maneira eficiente com os professores, além da organização do seu tempo e horários acadêmicos, bem como a planejar com antecedência a conclusão das tarefas (WHITE et al., 2017).

\section{Adaptações Didático-Pedagógicas}

A categoria Adaptações Didático-Pedagógicas incluiu as falas relacionadas às adaptações oferecidas pelas IES e às que foram consideradas necessárias pelos estudantes. A maioria dos participantes prefere realizar provas discursivas por poder discorrer com mais facilidade pelos assuntos que dominam, sem distratores e sem margem para interpretações dúbias.

O meu último colégio fazia um currículo, que no caso eu fazia uma prova adaptada, só que no caso não deixava a prova mais fácil, até deixava um pouco mais difícil (...) no caso... filosofia e sociologia , no caso a prova deles era inteira de marcar $\mathrm{X}$, a minha era inteira de escrever. (P1).

(...) porque a minha dificuldade são as instruções. Não é o conteúdo. (P2).

Eu gosto de provas que são equilibradas, não tem pegadinha. Não é aquela coisa de bote "não" na frente ou marque a "incorreta". (P4).

Nas provas subjetivas, redação, uma prova construída você tem o espaço para explicar o raciocínio (...) para mim é mais fácil do que uma questão que já vem pronta e você vai ter que achar a fórmula. (P5).

Os discursos reforçam achados de outros pesquisadores que apontam que questões de provas com margem para outras interpretações podem ser especialmente difíceis para os estudantes com TEA. Limitar a ambiguidade e fornecer orientações concretas e explícitas é uma estratégia que funciona muito bem para os autistas (BROWN; COOMES, 2016).

Alguns alunos podem sentir necessidade de um tempo ampliado para realização das avaliações ou outras atividades.

Ele só dá 40 minutos para fazer a prova. E eu achei isso muito pouco tempo porque eu gosto de estudar a prova. Fazer esquemas e tal porque eu quero ir muito bem porque essa também é minha matéria favorita. (P1).

Para Anderson e Butt (2017), muitos adultos jovens com TEA são cognitivamente capazes, talentosos e podem ter sucesso com preparação e apoio adequados, mas ainda são necessários estudos com amostras maiores e mais diversificadas para determinar 
http://dx.doi.org/10.5902/1984686X44082

quais práticas estão associadas ao sucesso de estudantes no espectro do autismo no ensino superior.

\section{Núcleos de Apoio}

A dificuldade no relacionamento com os profissionais do Núcleo de Apoio ficou bem evidente na fala deste participante:

\footnotetext{
De tarde eu tenho que ir lá fazer atendimentos (...) A pedagoga falou assim que se eu começasse a faltar ela ia cortar minha inclusão. E ela às vezes é grossa comigo ela fala assim: O gato comeu a sua língua? (...) Ela diz assim: "Você não vai me dar bom dia e um beijo hoje?". Aí ela me agarra, me abraça, me aperta, me fala que eu tenho que ser mais comunicativo com as pessoas. Que eu tenho que olhar no olho das pessoas. (P1).
}

Os achados da pesquisa corroboram evidências apontadas por outros estudos. Entre as razões citadas em revisão sistemática para não acessar núcleos de apoio, o motivo mais comum foi o "medo de ser estigmatizado", seguido por "querer tentar por conta própria", "acreditar que o serviço de apoio não ajudaria". Alguns referiram estar traumatizados com esse tipo de serviço para aceitar apoio, preferindo ficar sozinhos (ANDERSON; STEPHENSON; CARTER, 2017).

Alunos com TEA podem não procurar programas de apoio por não sentirem necessidade ou por não desejarem se identificar, embora possam se beneficiar dos suportes fornecidos (AMES et al., 2016). Pessoas que se sentem estigmatizadas são menos propensas a procurar ajuda (BROSNAN; MILLS, 2015).

Em outra revisão sistemática realizada por Kuder e Accardo (2018), os serviços de apoio mais prevalentes para estudantes autistas de nível superior eram aqueles que estavam disponíveis para qualquer aluno com NEE. O apoio oferecido pelas IES variava de mentoring a tempo extra em provas, locais alternativos para realizar as avaliações a aulas particulares, porém o treinamento de habilidades de comunicação social, o treinamento de habilidades sociais e o apoio psicossocial individualizado e personalizado demonstravam maior efetividade (KUDER; ACCARDO, 2017).

\section{Conhecimento do professor como recurso de adaptação}

Neste grupo foram incluídos os discursos relacionados a como o professor que conhece o TEA poderia atuar como facilitador da adaptação do autista à IES. 
http://dx.doi.org/10.5902/1984686X44082

Então, é uma luta minha e é muito interessante você ter isso, uma capacitação para os professores para eles poderem ajudar (...) alguma coisa assim que ajudasse os alunos a entenderem que isso é um problema, é uma dificuldade, é um transtorno e que você pode buscar tratamentos, pode buscar ajuda, você pode desenvolver estratégias para lidar com isso e que não tem nada de errado nisso. E uma coisa que eu vejo muito na educação inclusiva hoje em dia é não focar na dificuldade, mas focar na potencialidade, no que que você sabe fazer bem você consegue? Então vamos buscar recursos para que você consiga fazer isso (...) Eu acho que isso é essencial. Falta muito essa capacitação. (P4).

Hatfiel et al (2018) enfatizam a importância de uma abordagem individualizada e focada nos potenciais do estudante com TEA pelos professores. Considerar os estilos de aprendizagem do adolescente pode aumentar o sucesso na transição para o ensino superior.

Considerando que a inclusão tem importante relação com a formação e atuação do professor, entende-se necessário que a IES oriente o corpo docente a respeito das ações e habilidades que o professor deve apresentar, não apenas para atender à demanda, mas como um importante elemento de qualidade de ensino (ROSIN-PINOLA; DEL-PRETTE, 2014).

Para Rauli et al (2019), para além da dimensão física, é preciso encontrar caminhos para que a inclusão se efetive no contexto da sala de aula, ou seja, no âmbito didáticopedagógico.

De maneira geral, os achados na pesquisa apontam para a necessidade de que as instituições de ensino superior invistam na capacitação do corpo docente e técnicoadministrativo de maneira a desenvolver um ambiente acadêmico acolhedor e inclusivo, capaz de atender as especificidades desta população.

\section{Considerações finais}

Apesar do sofrimento e das limitações impostas pelo TEA, alguns autistas permanecem "invisíveis" para as IES. Muitos se deparam, ao entrar no ensino superior, com dois eventos de suma importância em sua vida: a perda do atendimento pelos profissionais de saúde que possuem familiaridade com o TEA, mas atendem apenas crianças e adolescentes, e a perda do apoio psicopedagógico ao sair do ensino médio.

A proposição de investigar, através da perspectiva dos autistas, como se dá o processo de adaptação à universidade se revelou uma tarefa intensamente desafiadora e enriquecedora. O principal desafio foi ouvi-los como legítimos protagonistas na construção de mecanismos de inclusão e adaptação ao ensino superior. O enriquecimento se deu, 
principalmente, a partir das reflexões a respeito de suas angústias, anseios e dificuldades e com a compreensão de que, se o ensino superior se constitui em um desafio para um neurotípico, para o autista a imersão em um ambiente com tantos estímulos e com a exigência de habilidades sociais mais aprimoradas, é uma verdadeira batalha.

O universo reduzido da população estudada, aliada às características típicas dos indivíduos com TEA, dificultou o recrutamento para o estudo. Estudos sobre a inclusão de pessoas com TEA no ensino superior são incipientes, apesar do aumento do interesse pelo assunto nos últimos anos, consideramos necessário ampliar a escuta e continuar construindo conhecimento com os estudantes com TEA em estudos similares, além de pesquisas mais abrangentes de natureza qualitativa.

Medidas universais, disponíveis a todo o corpo acadêmico, com foco em promover a equidade, defender e valorizar a diversidade e educar a comunidade do campus fornecendo informações sobre o TEA são necessárias não apenas para a inclusão do autista, mas para a construção de uma sociedade mais justa para todos.

\section{Referências}

ADREON, Diane; DUROCHER, Jennifer Stella. Evaluating the college transition needs of individuals with high-functioning autism spectrum disorders. Intervention in School and Clinic, v. 42, n. 5, p. $271-279,2007$.

AMEIS, Stephanie. H.; CATANI, Marco. Altered white matter connectivity as a neural substrate for social impairment in Autism Spectrum Disorder. Cortex, v. 62, p. 158 -181, 2015.

AMERICAN PSYCHIATRIC ASSOCIATION. DSM-5 Manual Diagnóstico e Estatísticos de Transtornos Mentais. 5. ed. Porto Alegre: Artmed, 2013.

AMES, Megan E. et al. Overview and Evaluation of a Mentorship Program for University Students with ASD. Focus on Autism and Other Developmental Disabilities, v. 31, n. $1,2016$.

ANDERSON, Anastasia H.; STEPHENSON, Jennifer; CARTER, Mark. A systematic literature review of the experiences and supports of students with autism spectrum disorder in post-secondary education. Research in Autism Spectrum Disorders, v. 39, p. $33-53,2017$.

ANDERSON, Connie; BUTT, Catherine. Young Adults on the Autism Spectrum at College: Successes and Stumbling Blocks. Journal of Autism and Developmental Disorders, v. 47, n. 10, p. $3029-3039,2017$. 
ASSUMPÇÃO JÚNIOR, Francisco Baptista; KUCZYNSKI, Evelyn. Autismo Infantil: novas tendências e perspectivas. 2. ed. ed. Rio de Janeiro: Atheneu, 2015.

ASSUMPÇÃO JÚNIOR, Francisco Baptista; PIMENTEL, Ana Cristina Mageste. Autismo infantil. International Review of Psychiatry, v. 22, n. Supl I, p. 37 - 39, 122000.

AZEVEDO, Sérgio Luiz Malta de et al. Inclusão e acessibilidade para pessoas cegas na Universidade Federal de Campina Grande. REIN-Revista Educação Inclusiva. Campina Grande, v. 3, n. 2, p. 17-27, 2019.

BAIO, Jon et al. Prevalence of autism spectrum disorder among children aged 8 yearsautism and developmental disabilities monitoring network, 11 sites, United States, 2014. MMWR Surveillance Summaries, v. 67, n. 6, p. 1, 2018.

BARDIN, Laurence. Análise de Conteúdo. 4ª ed. Lisboa: Edições 70, 2011.

BLEULER, Eugen. Dementia Praecox ou o Grupo das Esquizofrenias. [S.I.: s.n.], 1911.

BRASIL. Lei 9.394 de 20 de dezembro de 1996. Estabelece as diretrizes e bases da educação nacional, 1996. Disponível em:

http://www.planalto.gov.br/ccivil_03/leis//9394.htm. Acesso em: 29/04/2017.

BRASIL. Ministério da Educação. Política nacional de educação especial na perspectiva da educação inclusiva. Secretaria de Educação Especial, Brasília, 2008. Disponível em: http://portal.mec.gov.br/arquivos/pdf/politicaeducespecial.pdf. Acesso em: 27/03/2017.

BRASIL. Decreto № 6.949 de 25 de agosto de 2009. Convenção sobre os direitos das pessoas com deficiência, Brasília-DF, Agosto 2009. Disponível em:

http://www.planalto.gov.br/ccivil_03/_ato2007-2010/2009/decreto/d6949.htm. Acesso em: 23/12/2017.

BRASIL. Decreto 8368 de 2 de dezembro de 2014, Regulamenta a Lei no 12.764, de 27 de dezembro de 2012, que institui a Política Nacional de Proteção dos Direitos da Pessoa com Transtorno do Espectro Autista. 2014. Disponível em:

http://www.planalto.gov.br/ccivil_03/_ato2011-2014/2014/Decreto/D8368.htm. Acesso em: 03/04/2017.

BRASIL. Lei 13.146 de 6 de julho de 2015. Institui a Lei Brasileira de Inclusão da Pessoa com Deficiência (Estatuto da Pessoa com Deficiência), 2015. Disponível em: http://www.planalto.gov.br/ccivil_03/_ato2015-2018/2015/Lei/L13146.htm. Acesso em: 03/04/2017.

BROSNAN, Mark; MILLS, Elizabeth. The effect of diagnostic labels on the affective responses of college students towards peers with 'Asperger's Syndrome' and 'Autism Spectrum Disorder'. Autism, v. 20, n. 4, p. 388-394, 2016. 
BROWN, Kirsten R.; COOMES, Michael D. A spectrum of support: current and best practices for students with Autism Spectrum Disorder (ASD) at community colleges. Community College Journal of Research and Practice, v. 40, n. 6, p. $465-479,2016$.

BURGUESS, Rebecca. Understanding The Spectrum - A Comic Strip Explanation. 2017. Página web. Disponível em: www.https://the-art-of-autism.com/wpcontent/uploads/2017/11/ UnderstandtheSpectrum.pdf. Acesso em: 02/10/2018.

CARAYOL, Jerome et al. Autism risk assessment in siblings of affected children using sexspecific genetic scores. Molecular Autism, BioMed Central, v. 2, p. 17, 2011.

CHANG, Yi-Shin et al. Autism and Sensory Processing Disorders: Shared White Matter Disruption in Sensory Pathways but Divergent Connectivity in Social-Emotional Pathways. PLoS ONE, v. 9, n. 7, 2014.

COX, Bradley E. et al. College Experiences for Students With Autism Spectrum Disorder: Personal Identity, Public Disclosure, and Institutional Support. Journal of College Student Development, v. 58, n. 1, p. $71-87,2017$.

CRESPI, Bernard J. Autism As a Disorder of High Intelligence. Frontiers in Neuroscience, Frontiers Media S.A., v. 10, p. 300, 2016.

CULLEN, Jennifer A. The Needs of College Students with Autism Spectrum Disorders and Asperger's Syndrome. Journal of Postsecondary Education and Disability, v. 28, n. 1, p. $89-101,2015$.

DIAS SOBRINHO, José. Democratização, qualidade e crise da educação superior: faces da exclusão e limites da inclusão. Educação \& Sociedade, v. 31, n. 113, p. 1223 - 1245, 2010.

FRYE, Richard E. Social Skills Deficits in Autism Spectrum Disorder: Potential Biological Origins and Progress in Developing Therapeutic Agents. CNS Drugs, v. 32, n. 8, p. $713-$ 734, 2018.

GATTI, Bernardete. A formação de professores no Brasil: características e problemas. Educ. Soc., v. 31, n. 113, p. 1355 - 1379, 2010.

GELBAR, Nicholas W.; SMITH, Isaac; REICHOW, Brian. Systematic review of articles describing experience and supports of individuals with autism enrolled in college and university programs. Journal of Autism and Developmental Disorders, v. 44, n. 10, p. $2593-2601,2014$.

GILLESPIE-LYNCH, Kristen et al. Changing College Students' Conceptions of Autism: An Online Training to Increase Knowledge and Decrease Stigma. v. 45, n. 8, p. 2553 - 2566, 2015.

GILLESPIE-LYNCH, Kristen et al. "For a long time our voices have been hushed": Using student perspectives to develop supports for neurodiverse college students. Frontiers in Psychology, v. 8, p. 544, 2017. 
GLAT, Rosana; FERNANDES, Edicléa Mascarenhas. Da Educação Segregada à Educação Inclusiva: uma Breve Reflexão sobre os Paradigmas Educacionais no Contexto da Educação Especial Brasileira. Revista Inclusão, v. 1, n. 01, p. 34 - 39, 2005.

GOFFMAN, Erving. Estigma: notas sobre a manipulação da identidade deteriorada. 4. ed. Rio de Janeiro: LTC Editora, 1988.

HAHAMY, Avital; BEHRMANN, Marlene; MALACH, Rafael. The Idiosyncratic Brain: distortion of spontaneous connectivity patterns in autism spectrum disorder. Nature Neuroscience, v. 18, n. 2, p. 302, 2015.

HALIM, Andrew T.; RICHDALE, Amanda L.; ULJAREVIc,' Mirko. Exploring the nature of anxiety in young adults on the autism spectrum: A qualitative study. Research in Autism Spectrum Disorders, Elsevier, v. 55, p. 25 - 37, 2018.

HATFIELD, Megan et al. Factors related to successful transition planning for adolescents on the autism spectrum. Journal of Research in Special Educational Needs, v. 18, n. 1, p. $3-14,2018$.

\section{INSTITUTO NACIONAL DE ESTUDOS E PESQUISAS EDUCACIONAIS ANÍSIO} TEIXEIRA. Resumo técnico: Censo da Educação Superior 2017. 2018.

KERNS, Connor Morrow et al. Anxiety Disorders Interview Schedule-Autism Addendum: Reliability and Validity in Children With Autism Spectrum Disorder. Journal of Clinical Child and Adolescent Psychology, v. 46, n. 1, p. 88-100, 2017.

KUDER, S. Jay; ACCARDO, Amy. What Works for College Students with Autism Spectrum Disorder. Journal of Autism and Developmental Disorders, v. 48, n. 3, p. 722 $-731,2017$.

LAI, Meng-Chuan; LOMBARDO, Michael V.; BARON-COHEN, Simon. Autism. The Lancet, v. 383, n. 9920, p. $896-910,2013$.

MATTHEWS, Nicole L.; LY, Agnes R.; GOLDBERG, Wendy A. College Students' Perceptions of Peers with Autism Spectrum Disorder. Journal of Autism and Developmental Disorders, v. 45, n. 1, p. $90-99,2015$.

MAZEFSKY, Carla A. et al. Genetic and Environmental Influences on Symptom Domains in Twins and Siblings with Autism. Research in autism spectrum disorders, v. 2, n. 2, p. $320-331,2008$.

MIRANDA, Theresinha Guimarães; GALVÃO FILHO, Teófilo Alves. O professor e a educação inclusiva: Formação, práticas e lugares. Salvador: EDUFBA, 2012.

MORETT, Felipe Azevedo; HÜBNER, Maria Martha Costa. O estresse e a máquina de moer alunos do ensino superior: vamos repensar nossa política educacional? Revista Psicopedagogia, São Paulo, v. 34, n. 105, p. 258 - 267, 2017. 
ORGANIZACÃO MUNDIAL DA SAÚDE. CID-10: Classificação Estatística Internacional de Doenças e Problemas Relacionados à Saúde. 10. ed. São Paulo: EDUSP, 1993. v. 1. $1200 \mathrm{p}$.

RAPIN, Isabelle; TUCHMAN, Roberto F. Onde estamos: Visão geral e definições. Autismo: Abordagem Neurobiológica. Porto Alegre: Artmed, 2009.

RAULI, Patricia Maria Forte et al. Inclusão e acessibilidade no ensino superior: ações de sensibilização e formação docente. Anais do XVI Encontro de Ensino Pesquisa e Extensão das Faculdades Pequeno Príncipe. Curitiba: Faculdades Pequeno Príncipe, 2019.

ROBERTS, Nicole; BIRMINGHAM, Elina. Mentoring University Students with ASD: A Mentee-centered Approach. Journal of Autism and Developmental Disorders, v. 47, n. 4, 2017.

ROSIN-PINOLA, Andréa Regina; DEL-PRETTE, Zilda Aparecida Pereira. Inclusão escolar, formação de professores e a assessoria baseada em habilidades sociais educativas. Revista Brasileira de Educação Especial, Marilia, v. 20, n. 3, p. 341 - 356, 2014.

RUARO, Laurete Maria.; BEHRENS, Marilda Aparecida. Formação Do Professor Do Universitário: Olhar Brasileiro E Espanhol. Debates em Educação, v. 6, n. 12, p. 38 - 56, 2014.

RUZICH, Emily. et al. Measuring autistic traits in the general population: A systematic review of the Autism-Spectrum Quotient (AQ) in a nonclinical population sample of 6,900 typical adult males and females. Molecular Autism, v. 6, n. 1, p. 1 - 12, 2015.

SADOCK, Benjamin J.; SADOCK, Virginia A.; RUIZ, Pedro. Compêndio de Psiquiatria.Ciência do Comportamento e Psiquiatria Clínica. 11. ed. Porto Alegre: Artmed, 2017.

SANTIAGO, Mylene Cristina; SANTOS, Mônica Pereira dos. Planejamento de Estratégias para o Processo de Inclusão: desafios em questão. Educação \& Realidade, Porto Alegre, v. 40, n. 2, p. $485-502,2015$.

SARRETT, Jennifer C. Autism and Accommodations in Higher Education: Insights from the Autism Community. Journal of Autism and Developmental Disorders, v. 48, n. 3, p. $679-693,2018$.

SHMULSKY, Solvegi; GOBBO, Ken. Autism Spectrum in the College Classroom: Strategies for Instructors. Community College Journal of Research and Practice, v. 37, n. 6, p. $490-495,2013$.

SILVA, Andressa Hennig; FOSSÁ, Maria Ivete Trevisan. Análise De Conteúdo: Exemplo De Aplicação Da Técnica Para Análise De Dados Qualitativos. Qualit@s Revista Eletrônica, v. 16, n. 1, 2015. 
SWAIN, Deanna et al. Emotion Dysregulation and Anxiety in Adults with ASD: Does Social Motivation Play a Role? Journal of Autism and Developmental Disorders, v. 45, n. 12, p. $1-7,2015$.

TAVARES, Lídia Mara Fernandes Lopes; SANTOS, Larissa Medeiros Marinho dos; FREITAS, Maria Nivalda Carvalho. A Educação Inclusiva: um Estudo sobre a Formação Docente. Revista Brasileira de Educação Especial, Marília, SP, v. 22, n. 4, p. 527 542, 2016.

VAN HEES, Valérie; MOYSON, Tinneke; ROEYERS, Herbert. Higher education experiences of students with autism spectrum disorder: Challenges, benefits and support needs. Journal of autism and developmental disorders, v. 45, n. 6, p. 1673-1688, 2015.

VANBERGEIJK, Ernst; KLIN, Ami; VOLKMAR, Fred. Supporting more able students on the autism spectrum: College and beyond. Journal of autism and developmental disorders, v. 38, n. 7, p. $1359-1370,2008$.

VOLKMAR, Fred R.; WOLF, Julie M. When children with autism become adults. World Psychiatry, v. 12, n. 1, p. $79-80,2013$.

WATERHOUSE, Lynn. Rethinking Autism: Variation and Complexity. Academic Press, 2013.

WEHMAN, P. et al. Transition From School to Adulthood for Youth With Autism Spectrum Disorder: What We Know and What We Need to Know. Journal of Disability Policy Studies, v. 25, n. 1, p. $30-40,2014$.

WHITE, Susan. W. et al. Development of a College Transition and Support Program for Students with Autism Spectrum Disorder. Journal of Autism and Developmental Disorders, v. 47, n. 10, p. 3072 - 3078, 2017.

WONG, Connie et al. Evidence-Based Practices for Children, Youth, and Young Adults with Autism Spectrum Disorder: A Comprehensive Review. Journal of Autism and Developmental Disorders, v. 45, n. 7, p. 1951 - 1966, 2015.

\section{Correspondência}

Claudia Paola Carrasco Aguilar - Faculdades Pequeno Príncipe, Avenida Iguaçu, 333, Rebouças, Curitiba, Paraná - Brasil.

CEP: 80230-020

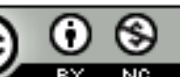

This work is licensed under a Creative Commons Attribution-NonCommercial 4.0 International (CC BY-NC 4.0) 